\title{
Impairment of the autophagy-lysosomal pathway and activation of pyroptosis in macular corneal dystrophy
}

\author{
Tao Zheng (1)', Chuchu Zhao', Baowen Zhao ${ }^{1}$, Hanruo Liu², Shijian Wang ${ }^{1}$, Liyuan Wang ${ }^{1}$ and Ping Liu (1)
}

\begin{abstract}
Macular corneal dystrophy (MCD) is ascribed to mutations in the carbohydrate sulfotransferase (CHST6) gene affecting keratan sulfate (KS) hydrophilicity and causing non-sulfated KS to precipitate in keratocytes and the corneal stroma. We investigated roles for inflammatory responses in MCD pathogenesis by examining the lysosomal-autophagy pathway and activation of pyroptosis in MCD keratocytes. Normal and lesioned keratocytes were obtained from MCD patients undergoing corneal transplantation. The keratocytes were subjected to gene sequencing, RT-PCR, western blotting, transmission electron microscopy, histological staining, induction and inhibition assays of autophagy and pyroptosis, CCK-8 and LysoTracker Green DND-26 labeling, and flow cytometry. A novel homozygous MCD mutation was identified in a family from Northeast China; the mutation was distinguished by cytoplasmic vacuolation, cell membrane disruption, electron dense deposits, and deposition of a band of Periodic acid-Schiff and Alcian bluepositive material in the keratocytes and stroma layer. KS protein levels were decreased, expression of p62 and LC3-II proteins was enhanced, cathepsin D expression was declined and the LysoTracker Green DND-26 signal was dramatically reduced in MCD keratocytes. Bafilomycin-A1 treatment significantly increased caspase-1 and Pro-IL-1 $\beta$ expression in normal and MCD keratocytes. Nod-like receptors pyrins-3 (NLRP3), caspase-1, Pro-IL-1 $\beta$, and IL-1 $\beta$ levels were pronouncedly elevated in cells exposed to $\mathrm{H}_{2} \mathrm{O}_{2}$. Ac-YVAD-CMK treatment reversed this expression in normal and MCD keratocytes. Suppression of the autophagic degradation of non-sulfated KS by impaired autophagic flux in MCD keratocytes triggers pyroptosis. Amelioration of impaired autophagy and restraint of pyroptosis may, therefore, have therapeutic efficacy in the treatment of MCD.
\end{abstract}

\section{Introduction}

Macular corneal dystrophy (MCD, OMIM217800), also known as Groenouw II type corneal dystrophy, is a rare autosomal recessive-inherited condition characterized by progressive loss of vision, photophobia, and discomfort on the ocular surface. The symptom of a diffuse, foggy corneal stroma progresses from a focal, patchy, white opacity with unclear boundaries to keratoleukoma in both eyes

\footnotetext{
Correspondence: Liyuan Wang (oriensan@126.com) or

Ping Liu (ping_liu53@hotmail.com)

'Department of Ophthalmology, The First Affiliated Hospital of Harbin Medical University, Harbin 150001, China

${ }^{2}$ The Beijing Institute of Ophthalmology, Beijing Tongren Hospital, Capital Medical University, Beijing 100730, China

Edited by Inna Lavrik
}

and finally cornea thinning, as determined by ocular slit lamp examination ${ }^{1}$. MCD has a high prevalence in India, Saudi Arabia, and Iceland due to increased rates of mutation in the CHST6 gene, and this prevalence can largely be ascribed to consanguinity ${ }^{2}$. The most effective short-term treatment for recovery of sight acuity in MCD is keratoplasty and deep anterior lamellar corneal transplantation ${ }^{3}$. However, recurrence after keratoplasty and complications such as graft rejection and endothelial cell loss following transplantation have been documented ${ }^{4}$. Research on gene and drug therapies for MCD is, therefore, urgently required.

The pathogenic gene of MCD is CHST6, which encodes corneal $\mathrm{N}$-acetylglucosamine-6-sulfphotransferase (GlcNAc6ST)

\section{(c) The Author(s) 2020}

(c) (i) Open Access This article is licensed under a Creative Commons Attribution 4.0 International License, which permits use, sharing, adaptation, distribution and reproduction cc) in any medium or format, as long as you give appropriate credit to the original author(s) and the source, provide a link to the Creative Commons license, and indicate if changes were made. The images or other third party material in this article are included in the article's Creative Commons license, unless indicated otherwise in a credit line to the material. If material is not included in the article's Creative Commons license and your intended use is not permitted by statutory regulation or exceeds the permitted use, you will need to obtain permission directly from the copyright holder. To view a copy of this license, visit http://creativecommons.org/licenses/by/4.0/. 
and is located on chromosome 16 (16q22) (ref. ${ }^{5}$ ). Sulfated KS, formed by the action of GlcNAc6ST, is transported to the extracellular matrix (ECM), where it participates in the formation of some components of the corneal stroma and serves as a critical corneal adhesive ${ }^{6,7}$. Sulfated KS is abundantly present in the corneal stromal layer, the pro-elastic layer, and the postelastic layer; however, expression of sulfated KS is low in the epithelium, endothelium, and keratocyte in normal corneal tissues $^{8}$. Mutation of the CHST6 gene results in accumulation of large amounts of non-sulfated KS (usually absent in the normal cornea) and its deposition in the keratocytes and in the ECM of the corneal stroma, leading to keratocytes injury and corneal tissue opacity,

Accumulation of non-sulfated KS due to the CHST6 gene mutation may also affect the process of pyroptosis, also known as inflammatory necrosis. Pyroptosis is a kind of programmed cell death characterized by the continuous expansion of cells until the rupture of cell membranes leads to the release of intracellular contents and activation of a strong inflammatory response ${ }^{10}$. Pyroptosis is an important innate immune response triggered by various pathological stimuli, including microbial infections, cardiovascular diseases, central nervous system diseases, and malignant tumors ${ }^{11-14}$. The process begins with discernment of pathogen-related molecular patterns or damage-related molecular patterns (DAMPs) by Tolllike receptors as a priming or initiating signal. This triggers signaling by nuclear factor kappa $B$, which in turn upregulates transcription of inflammasome-related components, including inactive NLRP3, pro-IL-1 $\beta$, and proIL-18 (refs. ${ }^{15-18}$ ). Gasdermin-D (GSDMD), a newly identified executioner of pyroptotic cell death, is cleaved by activated caspase- 1 catalyzed by the NLRP3 inflammasome. Activated caspase- 1 also cleaves pro-IL-1 $\beta$ and pro-IL-18 into mature IL-1 $\beta$, and IL-18, which are released through GSDMD pores ${ }^{19}$.

Depositions of non-sulfated KS in the keratocytes eventually need to be degraded. A fine balance is required between the synthesis and degradation of macromolecules to maintain intracellular homeostasis. Turnover of intracellular components is subtly mediated and involves their delivery to lysosomes rich in hydrolases to form an autolysosome $\mathrm{e}^{20}$. Lysosomes, which are cellular organelles, play a fatal role in the degradation of macromolecules. To exert this degradative function, these organelles contain a variety of hydrolases in which cathepsins, a group of proteases enclosed in lysosomes, execute integral roles in producing lysosomal catabolites. Cathepsin D (CTSD) deficiency leads to the abnormal degradation of biological macromolecules in the body and their storage in lysosomes $^{21}$. Currently, several mutation types of CHST6associated MCD have been discovered in Northeast China $^{22}$. The present study reports the first homozygous MCD mutant in Northeast China. Some reports of
CHST6 variants resulting in MCD have been published, but the pathogenesis of MCD remains underexplored ${ }^{2}$. However, its pathological characteristics hint at the possible involvement of a strong inflammatory response. Non-sulfated KS is a DAMP molecule, so it may activate the pyroptosis pathway, leading to keratocyte membranes rupture and strong inflammation. Keratocytes show changes in their appearance following stimulation with pyroptosis inducers and inhibitors. In addition, a distinct lysosome dysfunction is observed in MCD keratocytes, which again may reflect a disturbance due to pyroptosis. The aim of the present study was to investigate the mechanisms underlying the progression of MCD to further elucidate the pathogenesis of MCD and to provide a reliable basis for future gene therapy and drug treatment of MCD.

\section{Results}

Reduced synthesis of sulfated KS and abnormal lysosome function in MCD keratocytes

In MCD type II (MCD II), the cornea and serum show antigenic KS responses ${ }^{23}$ but at levels lower than nor$\mathrm{mal}^{24,25}$. The measurements of sulfated KS in the present study indicated a higher expression of sulfated KS protein in normal keratocytes than in MCD keratocytes (Fig. 1a, b). The TEM images indicated accumulations of deposits in the stromal ECM as well as in the endoplasmic reticulum (ER) of the MCD keratocytes ${ }^{26}$, indirectly confirming that a large number of unsulfated KS was deposited in the MCD keratocytes.

The non-sulfated KS, as an anomalous compound in MCD keratocytes, was also probably metabolized by autophagy. We detected expression of the autophagy biomarker, LC3. C-terminal processing of LC3 produces LC3-I, which is modified to LC3-II with the initiation of autophagosome formation. We also detected p62 expression, which indicates autophagic flux ${ }^{27}$. The expression levels of p62 and LC3-II proteins were higher in MCD keratocytes than in normal keratocytes, hinting at an acceleration of autophagy and impairment of autophagic flux in MCD keratocytes (Fig. 1c-e).

Optimum lysosome function is best achieved at an acidic $\mathrm{pH}$. LysoTracker green is a lysosomophilic dye that allows monitoring of the $\mathrm{pH}$ sensitivity index of lysosomal function ${ }^{28}$. MCD keratocytes showed a loss of the LysoTracker signal when compared with similar observations in normal keratocytes (Fig. 1f, g), indicating a change in the lysosomal $\mathrm{pH}$ in MCD keratocytes. Lysosomal cathepsin activity is commonly used as an indicator of lysosomal function, and the CTSD, an aspartyl protease, plays a critical role in the degradation of macromolecules within autolysosomes ${ }^{29}$. The expression of CTSD at the protein level was higher in normal keratocytes than in MCD keratocytes (Fig. 1h, i), 


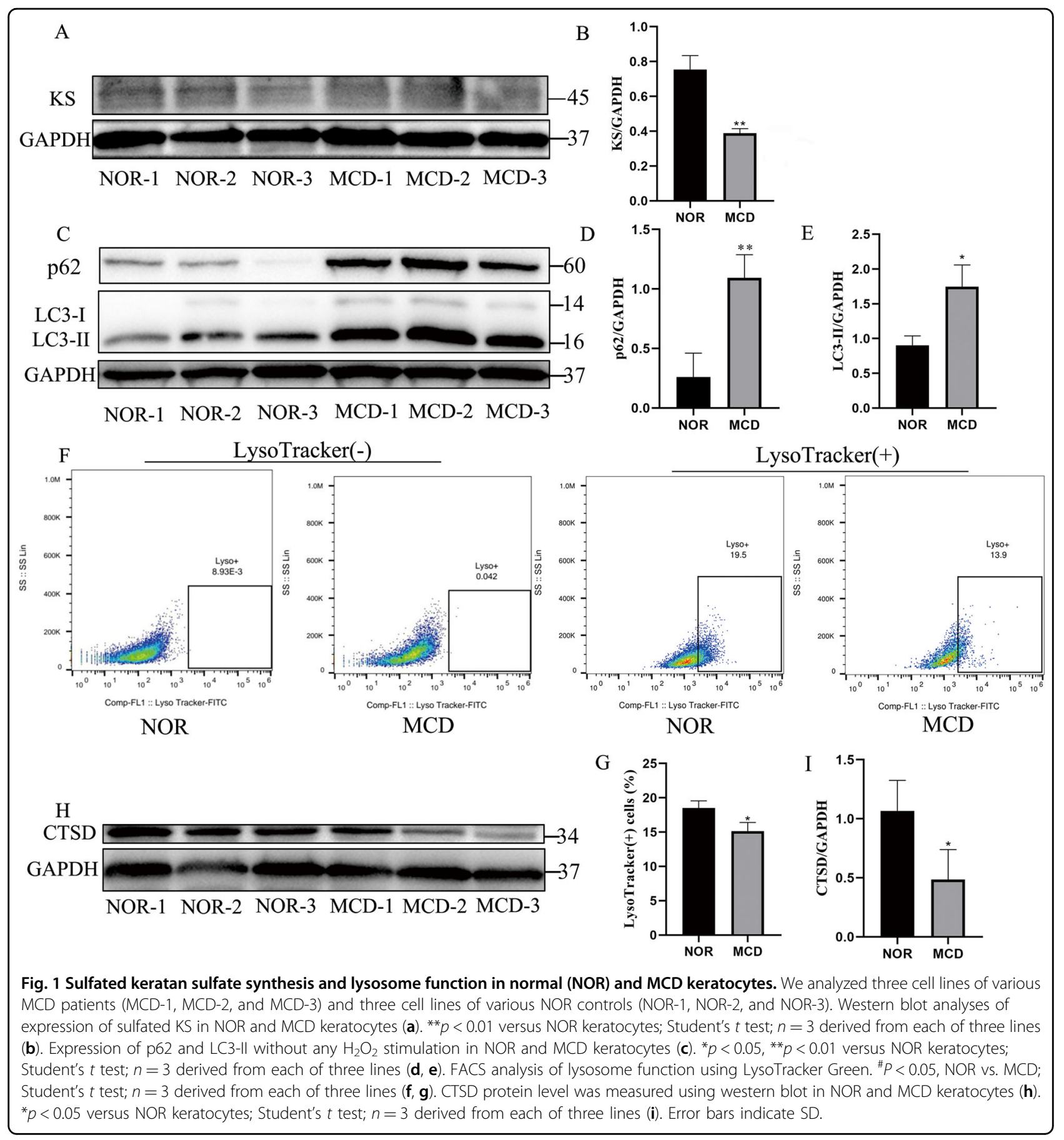

suggesting that autophagosomes accumulated because of the inhibition of autophagic degradation, e.g., because of a blockage of autophagosome-lysosome fusion or mitigation of lysosome content digestion due to decreased levels of CTSD ${ }^{30}$. The changes in lysosomal $\mathrm{pH}$ has been postulated to indicate that CTSD is a firstorder aspartic acid protease with a particularly acidic optimum $\mathrm{pH}$ and $\mathrm{pH}$-dependent maturity ${ }^{31}$, which would further account for the decreased CTSD in MCD keratocytes.

\section{Bafilomycin-A1 effects on autophagy and pyroptosis in normal and MCD keratocytes}

Bafilomycin-A1, an inhibitor of the vacuolar $\mathrm{H}^{+}$-ATPase ${ }^{32}$, boosted p62 and LC3-II protein levels in normal and MCD keratocytes, but the increase was 


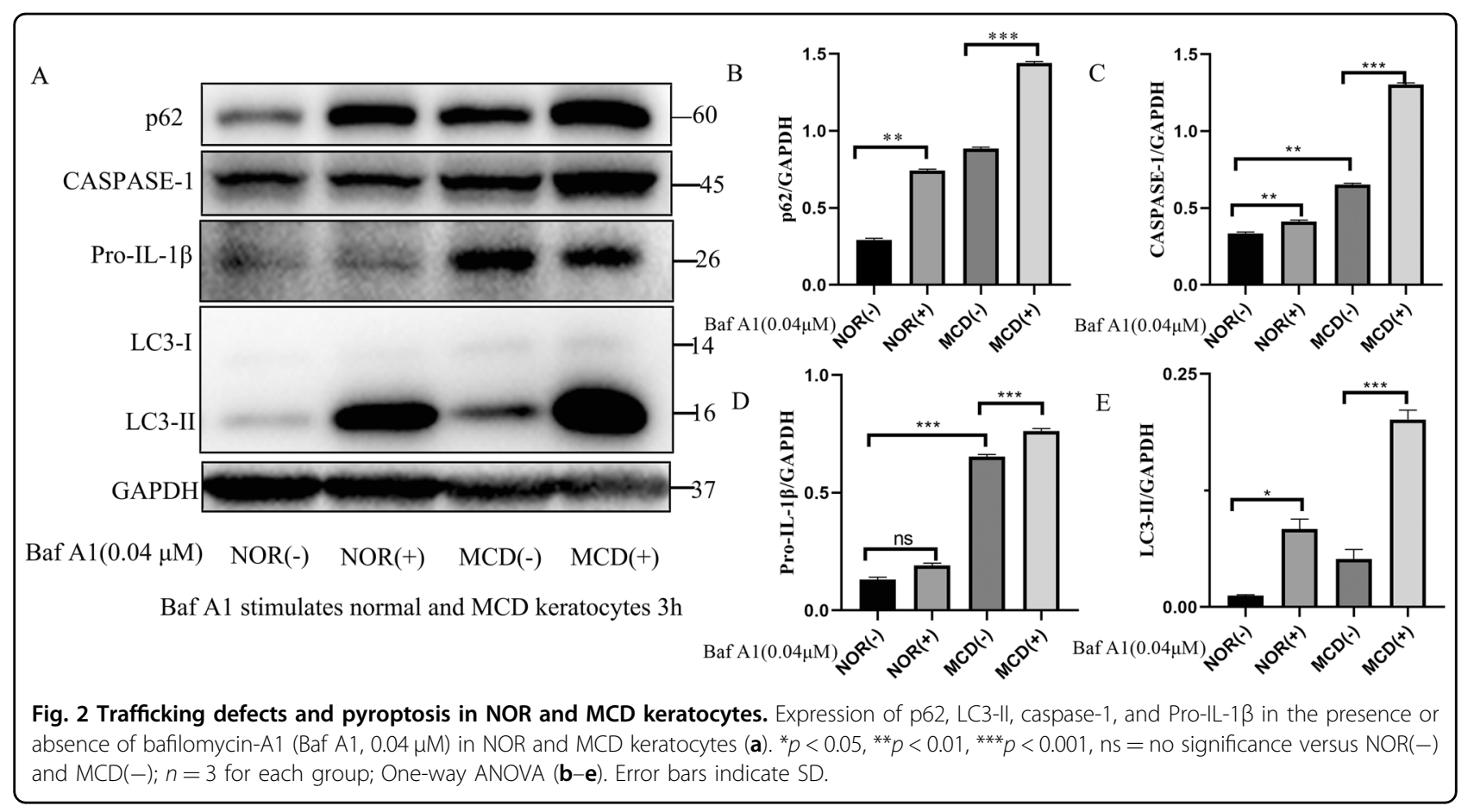

greater in the MCD keratocytes. This finding suggested that autophagy was facilitated and autophagic flux was blocked independent of the fusion of the autophagosomes with lysosomes in the MCD keratocytes (Fig. 2a, b, e). Pyroptosis differs from other types of cell death programs as it relies on caspase-1-mediated pathways. BafilomycinA1 significantly enhanced caspase- 1 and Pro-IL-1 $\beta$ protein levels in MCD keratocytes but not in normal keratocytes. The levels of the pyroptosis-related proteins caspase- 1 and Pro-IL-1 $\beta$ were still dramatically increased in MCD keratocytes even in the absence of bafilomycinA1, indicating a role for pyroptosis in MCD (Fig. 2a, c, d). Taken together, these results indicated a linkage between autophagy and pyroptosis in MCD, whereby impairment of autophagy accelerated pyroptosis. This suggested that MCD keratocytes with impaired autophagy may have an increased susceptibility to cell death and that non-sulfated KS rarely exists in normal keratocytes.

\section{Morphological hallmarks of MCD keratocytes}

Phase-contrast microscopy revealed that MCD keratocytes were enlarged, longer, and had an irregular arrangement when compared with normal keratocytes (Fig. 3a-d). The pathological changes may occur in MCD keratocytes at the subcellular (organelle) level. The TEM images revealed ultrastructural degenerative changes, including vacuole formation, incomplete cell membrane, and electron dense deposits, in MCD keratocytes that were almost absent from normal keratocytes (Fig. 3e-g). The phenotype of the MCD keratocytes was characterized by evaluating the growth rate and cell death rate of the MCD keratocytes. The rate of cell growth was significantly lower in the MCD than in the normal keratocytes (Fig. 3h). The morphological changes consisted with recent descriptions of pyroptotic cells, which are characterized by swelling, fragmentation of the cell membranes, and progression to cell rupture that causes an inflammatory reaction.

\section{Pyroptosis markers were increased in cultured keratocytes from MCD patients}

Caspase-1 is activated via the inflammatory initiation factor NLRP3 that drives GSDMD pore formation on the membrane and ultimately results in programmed execution of cell death ${ }^{33}$. Measurement of pyroptosisrepresentative proteins by western blotting revealed significantly higher levels of NLRP3, caspase-1, Pro-IL-1 $\beta$, IL-1 $\beta$, and GSDMD in MCD keratocytes than in normal keratocytes (Fig. 3i-n). RT-PCR analyses showed upregulated expression of pyroptosis marker mRNAs in MCD keratocytes (Fig. 3o-q), confirming a possible involvement of pyroptosis in the CHST6 mutation associated with MCD.

\section{A NLRP3 inducer $\left(\mathrm{H}_{2} \mathrm{O}_{2}\right)$ exacerbated cell pyroptosis in both normal and MCD keratocytes}

Pyroptosis can protect cells, but it may also contribute to cell death ${ }^{34}$. Exposure of normal and MCD keratocytes to different concentrations $(0-200 \mu \mathrm{M})$ of the reactive oxygen species (ROS) $\mathrm{H}_{2} \mathrm{O}_{2}$ for $6 \mathrm{~h}$ resulted in a 


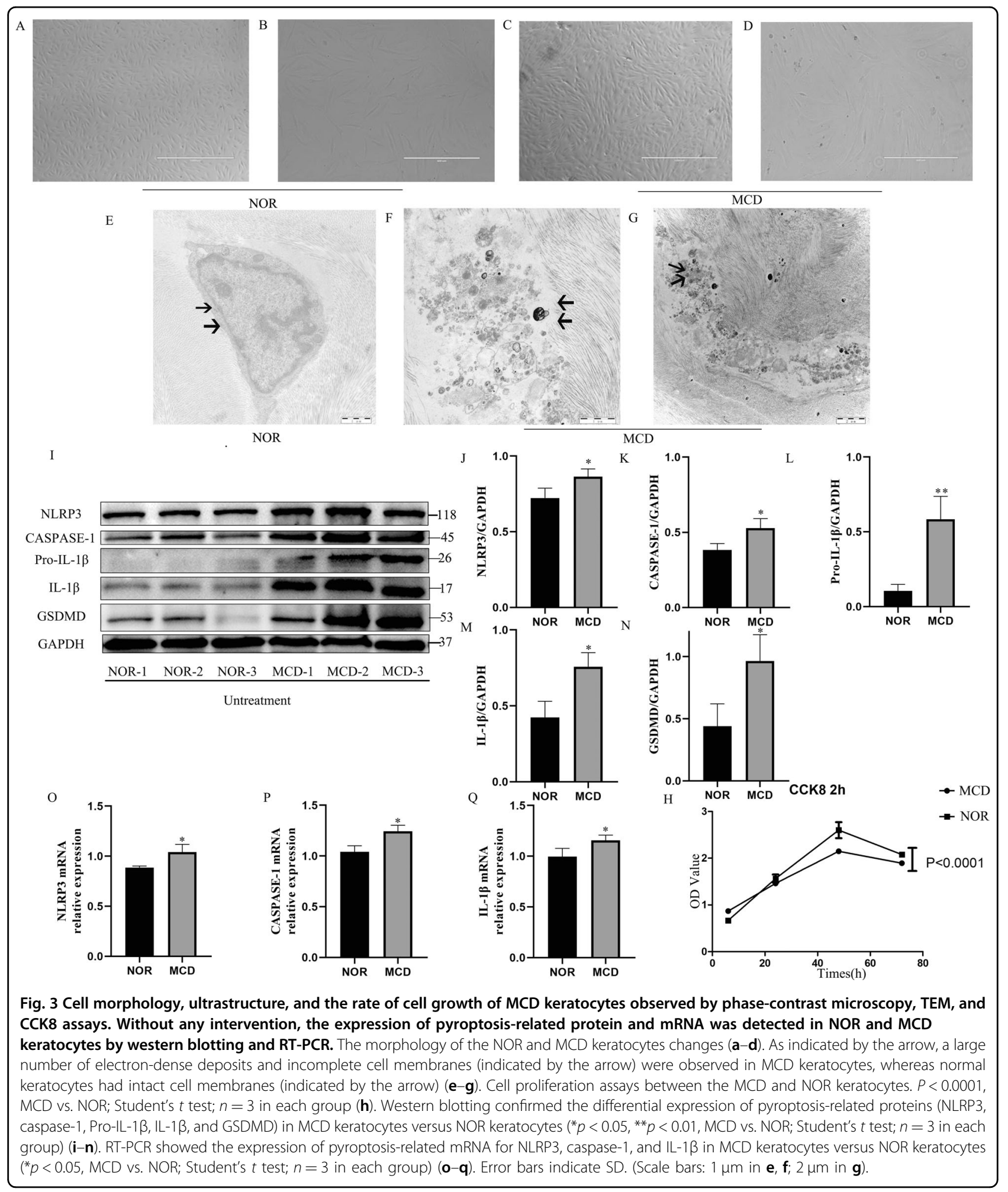

dose-dependent increase in levels of the pyroptosisrelated proteins NLRP3, caspase- 1 , Pro-IL-1 $\beta$, and IL-1 $\beta$ in both normal and MCD keratocytes, but the increases were greater in the MCD keratocytes. At higher $\mathrm{H}_{2} \mathrm{O}_{2}$ concentrations $(400-600 \mu \mathrm{M})$, the expression levels of NLRP3, caspase-1, Pro-IL-1 $\beta$, and IL- $1 \beta$ showed distinct decreases, which may have reflected increased cell death caused by high $\mathrm{H}_{2} \mathrm{O}_{2}$ concentrations (Fig. $4 \mathrm{a}-\mathrm{e}, \mathrm{f}-\mathrm{j}$ ). 


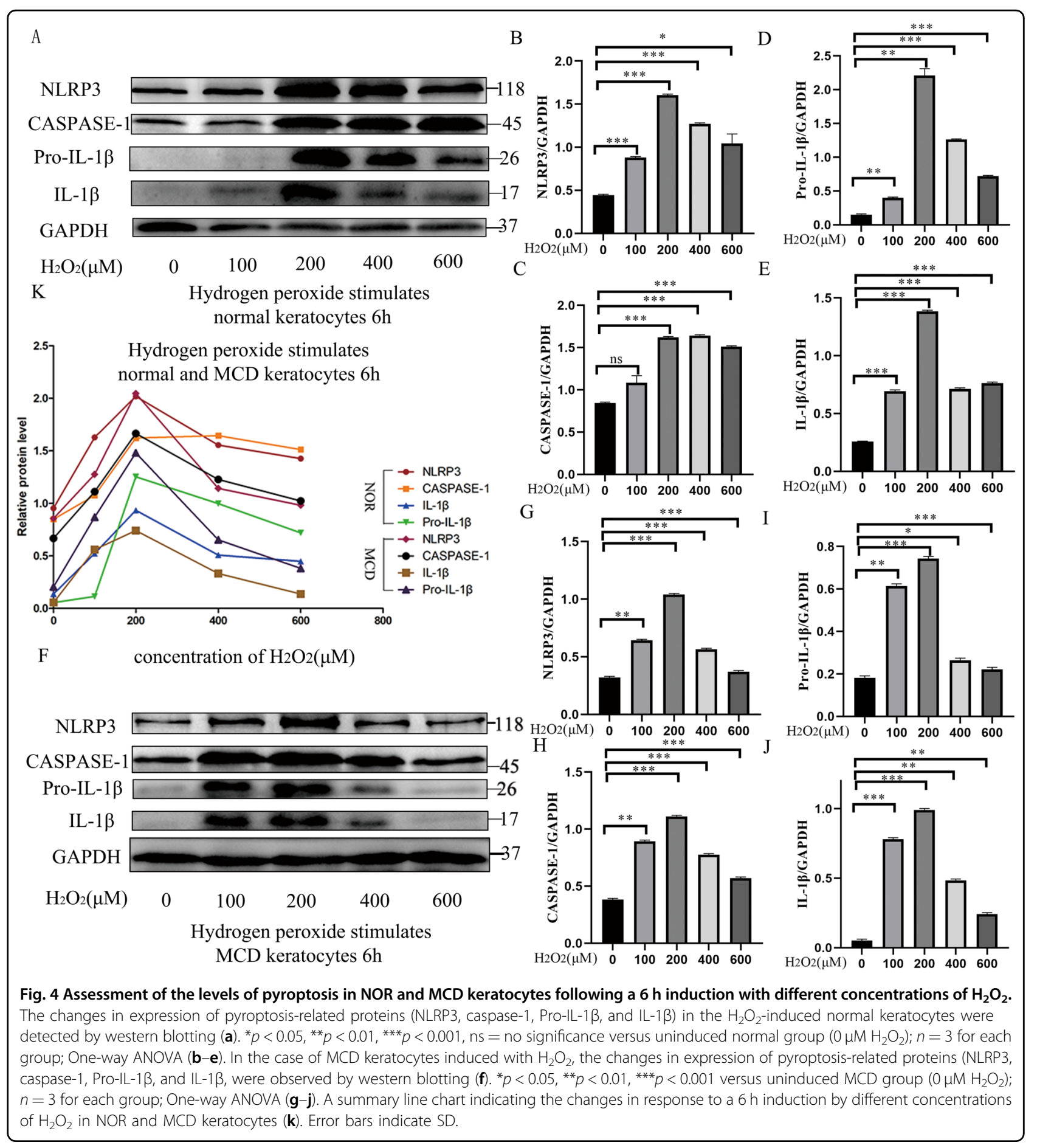

Figure 4k shows that the CHST6 mutation increased the susceptibility to $\mathrm{H}_{2} \mathrm{O}_{2}$-induced pyroptosis in MCD. All these results suggested activation of ROS-NLRP3 inflammasome-induced pyroptosis and an inflammatory pathway in cultured MCD keratocytes and further aggravation by $\mathrm{H}_{2} \mathrm{O}_{2}$ stimulation ${ }^{35}$.
Caspase-1 inhibitor, AC-YVAD-CMK, could attenuate the development of $\mathrm{H}_{2} \mathrm{O}_{2}$-induced pyroptosis in normal and MCD keratocytes

The caspase-1 inhibitor Ac-YVAD-CMK structurally resembles the catalytic substrate of caspase- 1 and irreversibly antagonizes caspase- 1 activity $^{36}$. Ac-YVAD-CMK 


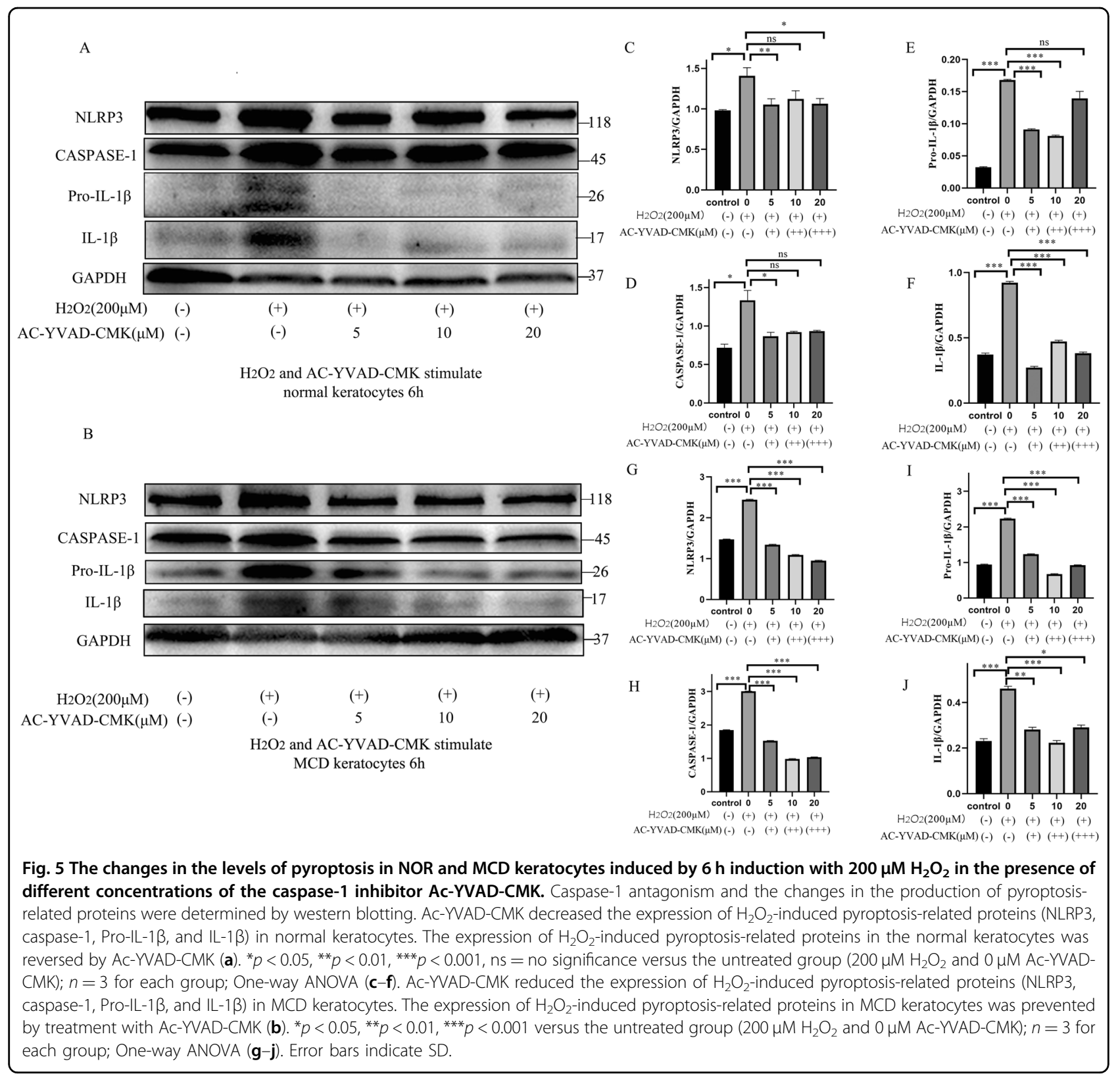

protects against $\mathrm{H}_{2} \mathrm{O}_{2}$-aggravated pyroptosis injury in normal and MCD keratocytes by suppressing caspase-1mediated pyroptotic cell death through downregulation of the protein expression of NLRP3 and caspase-1, as well as hampering Pro-IL-1 $\beta$ which was cleaved into mature IL$1 \beta$. Measurement of the expression of the NLRP3 inflammasome signaling pathway proteins (Fig. 5a, b) revealed that $\mathrm{H}_{2} \mathrm{O}_{2}$ induction significantly augmented the expression of pyroptosis-related proteins in the untreated group $\left(200 \mu \mathrm{M} \mathrm{H}_{2} \mathrm{O}_{2}\right.$ and $0 \mu \mathrm{M}$ Ac-YVAD-CMK), compared with the control $\left(0 \mu \mathrm{M} \mathrm{H}_{2} \mathrm{O}_{2}\right.$ and $0 \mu \mathrm{M}$ Ac-YVADCMK) normal and MCD keratocytes. However, AcYVAD-CMK treatment inhibited the NLRP3 inflammasome activation by downregulating the protein levels of NLRP3, caspase-1, Pro-IL-1 $\beta$, and IL-1 $\beta$ in normal and MCD keratocytes co-treated with $\mathrm{H}_{2} \mathrm{O}_{2}(200 \mu \mathrm{M})$ and with various doses of Ac-YVAD-CMK when compared with the untreated group $\left(200 \mu \mathrm{M} \mathrm{H}_{2} \mathrm{O}_{2}\right.$ and $0 \mu \mathrm{M}$ Ac-YVAD-CMK) (Fig. 5a, b). The expression of NLRP3, caspase- 1 , Pro-IL-1 $\beta$, and IL- $1 \beta$ protein was also dramatically downregulated by the inhibitor in normal and MCD keratocytes (Fig. $5 \mathrm{c}-\mathrm{j}$ ). The optimal concentration of Ac-YVAD-CMK appeared to be 5 and $10 \mu \mathrm{M}$ for suppression of pyroptosis in normal and MCD keratocytes induced by $200 \mu \mathrm{M} \mathrm{H}_{2} \mathrm{O}_{2}$ (Fig. 5a-j). Caspase- 1 inhibition reversed $\mathrm{H}_{2} \mathrm{O}_{2}$-aggravated pyroptosis by 


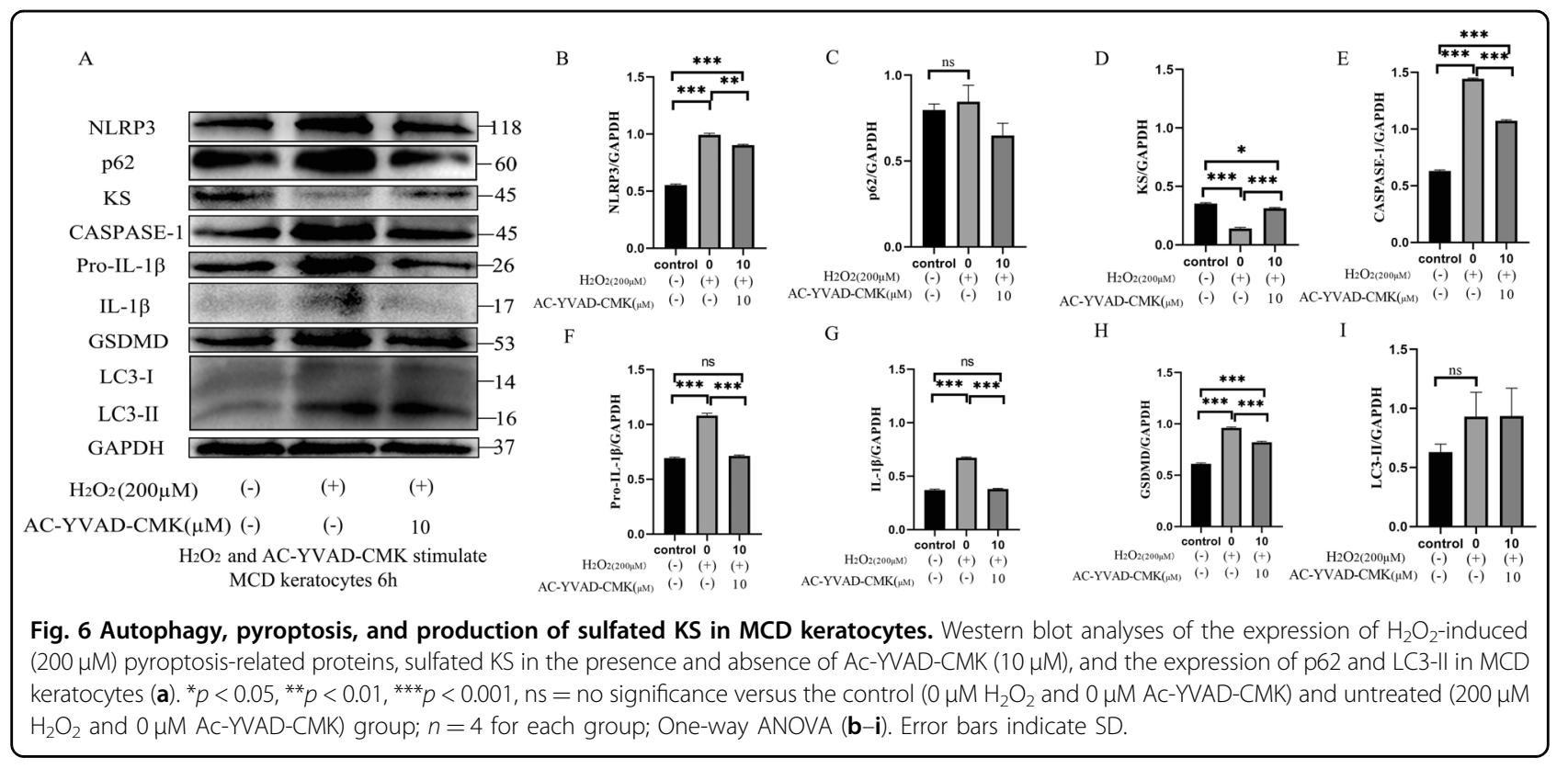

decreasing caspase- 1 activity and the production of precursor and mature IL- $1 \beta$ in normal and MCD keratocytes, implying that the protective effects of Ac-YVAD-CMK against $\mathrm{H}_{2} \mathrm{O}_{2}$-aggravated pyroptosis were mediated by its effects on caspase-1-dependent pyroptosis activation.

\section{$\mathrm{H}_{2} \mathrm{O}_{2}$ treatment revealed a relationship between sulfated $\mathrm{KS}$ and pyroptosis in MCD keratocytes}

Exogenous $\mathrm{H}_{2} \mathrm{O}_{2}$ induces autophagy, as demonstrated in many reports ${ }^{37-40}$, and our data indicated that $\mathrm{H}_{2} \mathrm{O}_{2}$ can induce pyroptosis. The expression of p62 and LC3-II proteins in $\mathrm{H}_{2} \mathrm{O}_{2}$-induced $(200 \mu \mathrm{M}) \mathrm{MCD}$ keratocytes changed meaninglessly from the levels in untreated $\left(200 \mu \mathrm{M} \mathrm{H}_{2} \mathrm{O}_{2}\right.$ and $0 \mu \mathrm{M}$ Ac-YVAD-CMK) and control $\left(0 \mu \mathrm{M} \mathrm{H}_{2} \mathrm{O}_{2}\right.$ and $0 \mu \mathrm{M}$ Ac-YVAD-CMK) group. However, pyroptosis-related proteins were significantly upregulated in $\mathrm{H}_{2} \mathrm{O}_{2}$-induced $(200 \mu \mathrm{M})$ MCD keratocytes compared with the control $\left(0 \mu \mathrm{M} \mathrm{H}_{2} \mathrm{O}_{2}\right.$ and $0 \mu \mathrm{M}$ Ac-YVAD-CMK) group (Fig. 6a-c, e-i), confirming that $\mathrm{H}_{2} \mathrm{O}_{2}(200 \mu \mathrm{M})$ had no pronounced effects on autophagy in MCD keratocytes. These results also showed that Ac-YVAD-CMK $(10 \mu \mathrm{M})$ can dramatically mitigate a $\mathrm{H}_{2} \mathrm{O}_{2}$-aggravated pyroptosis insult by decreasing NLRP3 inflammasome activation, thereby reducing the pyroptosis induced by activated caspase- 1 and the inflammatory response in MCD keratocytes (Fig. 6a, b, e-h).

Normal antigenic KS can also be detected in MCD keratocytes. Interestingly, the promotion of cell pyroptosis significantly reduced the expression of sulfated KS and the inhibition of cell pyroptosis distinctly augmented the expression of sulfated KS in MCD keratocytes (Fig. 6a, d). Previous evidence indicated that several small leucine-rich proteoglycans which were glycosylated with KS ultimately formed the KS proteoglycan (KSPG) and sustained the correct interfibrillar spacing of the collagen fibrils in the corneal tissue ${ }^{41}$. Non-sulfated KS has been discovered in MCD keratocytes, and it is produced in equivalent amounts to normal KS in the normal cornea. Antibodies to the core protein of normal KSPG react with the nonsulfated KSPG found in MCD I ${ }^{42}$. Thus, the non-sulfated KSPG may be expelled from the MCD keratocytes into the corneal stromal layer via cell pyroptosis, further aggravating the symptoms of MCD.

\section{Discussion}

The expression of p62 and LC3-II proteins was upregulated in MCD keratocytes compared with normal keratocytes, suggesting that autophagy was triggered and autophagic flux was impaired in MCD keratocytes. We suspected that MCD might cause disturbances in the autophagic degradative system as a result of autophagosome-lysosome fusion or lysosomal dysfunction. The autophagy inhibitor bafilomycin-A1 increased p62 and LC3-II protein levels in normal and MCD keratocytes, accompanied by a decrease in the LysoTracker signal and CTSD expression in MCD keratocytes. These findings supported the possibility that autophagy defects are likely due to lysosomal dysfunction in MCD.

Corneal glucosamine C-GlcNAc6ST is encoded by CHST6 on chromosome 16q22. This enzyme transfers sulfate to the unsulfated keratan chains, utilizing 3'-phospho-5'adenylyl sulfate as a sulfonate donor to catalyze the transfer of sulfate to position 6-O of the $\mathrm{N}$-acetyl-glucosamine of keratan in the cornea ${ }^{6,43}$. Mutations in C-GlcNAc6ST, such as in the $5^{\prime} \mathrm{PB}$ domain that contains an essential part of the active site responsible for $3^{\prime}$-phospho-5'-adenylyl sulfate 
binding, seriously impact sulfotransferase activity and result in the deposition of poorly sulfated and non-sulfated KS in the intracellular and extracellular matrix of the MCD cornea $^{44}$. In its non-sulfated form, KS was translocated via its signal peptide into the ER, where it then matured during passage through the Golgi. Non-sulfated KS may be secreted via Golgi-derived secretory vesicles into the cytoplasm, where it is ultimately deposited due to a lack of hydrophilicity. Accumulation of non-sulfated KS then persists due to impaired autophagy, and non-sulfated KS is eventually stored in the lysosomes. The non-sulfated KS that accumulates in MCD lysosomes might be secreted into the ECM via an unconventional autophagy-based secretory route recently reported for the extracellular delivery of IL- $1 \beta^{45}$. In the present study, $\mathrm{H}_{2} \mathrm{O}_{2}$-induced pyroptosis decreased the level of sulfated KS, while Ac-YVAD-CMK inhibition of pyroptosis restored the expression of sulfated KS in MCD keratocytes, probably by cuing non-sulfated KS excretion into the ECM via pyroptosis. Our previous research showed that expression of the ER stress marker protein GRP78 and $\mathrm{CHOP}$ protein were enhanced in MCD keratocytes and triggered the ER stress response and CHOP-mediated apoptosis $^{22}$. ER-associated degradation is tightly associated with the activation of ER stress and serves to eliminate misfolded proteins from the ER via the cytoplasmic ubiquitin-proteasome system ${ }^{46}$. Therefore, the non-sulfated KS that accumulates in the ER might also be degraded by the cytoplasmic ubiquitin-proteasome system. Aggregates of non-sulfated KS may undergo exocytosis mediated by Golgiderived secretory vesicles and exosome pathways via plasma membrane fusion and excretion into $\mathrm{ECM}^{47}$. These pathways for intracellular metabolism and secretion into ECM suggest the possibility that aggregates of non-sulfated KS might also be secreted by pyroptosis and ultimately be deposited in the corneal matrix to cause cornea opacity.

The ocular surface inflammatory status has been investigated in different types of $\mathrm{CD}^{48}$, but the potential molecules involved in the pathogenesis of the inflammatory response in MCD keratocytes remains underexplored. TEM and histochemical observations confirmed the presence of aggregations in the vacuolated cytoplasm, the occurrence of cell membrane rupture, and the accumulation of granular material in MCD keratocytes (Supplementary Fig. 1). The pyroptosis-related proteins NLRP3, caspase-1, Pro-IL-1 $\beta$, IL-1 $\beta$, and GSDMD were upregulated in MCD keratocytes, supporting an involvement of pyroptosis in MCD. Notably, the keratocytes were characterized by intracytoplasmic aggregations of hydrophobic, non-sulfated KS, which may be perceived as a DAMP, resulting in inflammatory processes that ultimately lead to disease progression. Our findings highlighted that canonical inflammasome-induced pyroptosis may play a major role in the inflammatory response of MCD. Canonical inflammasome-induced pyroptosis involves immune activators, such as DAMPs, pathogenrelated molecular patterns, other exogenous invaders, or environmental stress, that activate the interaction between the pyrin domains in NLRP3 and apoptosisassociated speck-like protein. The caspase recruitment domain of apoptosis-associated speck-like protein recruits procaspase- 1 to trigger caspase-1 generation of GSDMD$\mathrm{N}$, mature IL-1 $\beta$, and IL-18. This promotes cell membrane rupture and a pronounced inflammatory response $^{49}$. By contrast, the non-canonical pathway appears to involve the discernment of cytosolic lipopolysaccharide (LPS) from invading gram-negative bacteria by caspases (murine caspase-11 and human homologs caspase- 4 and 5), followed by direct cleavage of GSDMD by caspase-4/5/11 directly into a C-terminal fragment and an $\mathrm{N}$-terminal fragment. The $\mathrm{N}$-terminal domain of GSDMD forms extensive gasdermin pores and provokes caspase- 1 to cleave pro-IL- $1 \beta / 18$ in accordance with the canonical inflammasome-induced pyroptosis ${ }^{50}$. Previous work has shown that antigenic KS was absent from the corneas and blood sera of patients with MCD type I and was solely present in the keratocytes ${ }^{23}$. In MCD type II, normal antigenic KS was detected in both the cornea and serum but at lower levels than seen in normal keratocytes $^{24,25}$. These findings hint that pyroptosis may be involved in a phenotype of MCD that is potentially attributed to the cell membrane rupture causing the release of KS protein into the corneal stroma layer.

$\mathrm{H}_{2} \mathrm{O}_{2}$ treatment can promote the assembly and activation of the NLRP3 inflammasome, triggering caspase- 1 to initiate the production of IL- $1 \beta$, as well as IL- $18^{35} \cdot \mathrm{H}_{2} \mathrm{O}_{2}$ is also pivotal for autophagosome formation and autophagic degradation, as it mediates multiple signaling pathways. The oxidative signal is partially PI3K dependent and contributes to inhibition of Atg4, ultimately facilitating autophagy $^{51}$. ROS accumulation suppresses PI3K/AKT/ mTOR signaling and sequentially augments autophagy ${ }^{52}$. Our data demonstrated that the expression levels of p62, LC3-II, and pyroptosis-related proteins were increased in MCD keratocytes treated with $\mathrm{H}_{2} \mathrm{O}_{2}(200 \mu \mathrm{M})$. Therefore, $\mathrm{H}_{2} \mathrm{O}_{2}$-induced $(200 \mu \mathrm{M})$ pyroptosis was superior to induce autophagy in MCD keratocytes. However, we cannot rule out the possibility that the level of $\mathrm{H}_{2} \mathrm{O}_{2}$ used $(200 \mu \mathrm{M})$ was not sufficient for autophagy induction in our system. Administration of Ac-YVAD-CMK substantially diminished the protein-level expression of NLRP3, caspase-1, pro-IL-1 $\beta$, IL-1 $\beta$, and GSDMD in $\mathrm{H}_{2} \mathrm{O}_{2}$-induced MCD keratocytes. The treatment with AcYVAD-CMK inhibited $\mathrm{H}_{2} \mathrm{O}_{2}$-induced pyroptosis in MCD keratocytes apparently by restraining the expression of caspase-1 and production of pivotal downstream inflammatory cytokines (IL-1 $\beta$ and IL-18), as well as by hampering GSDMD cleavage. These results point to a vital therapeutic potential of caspase-1 inhibition that deserves clinical 


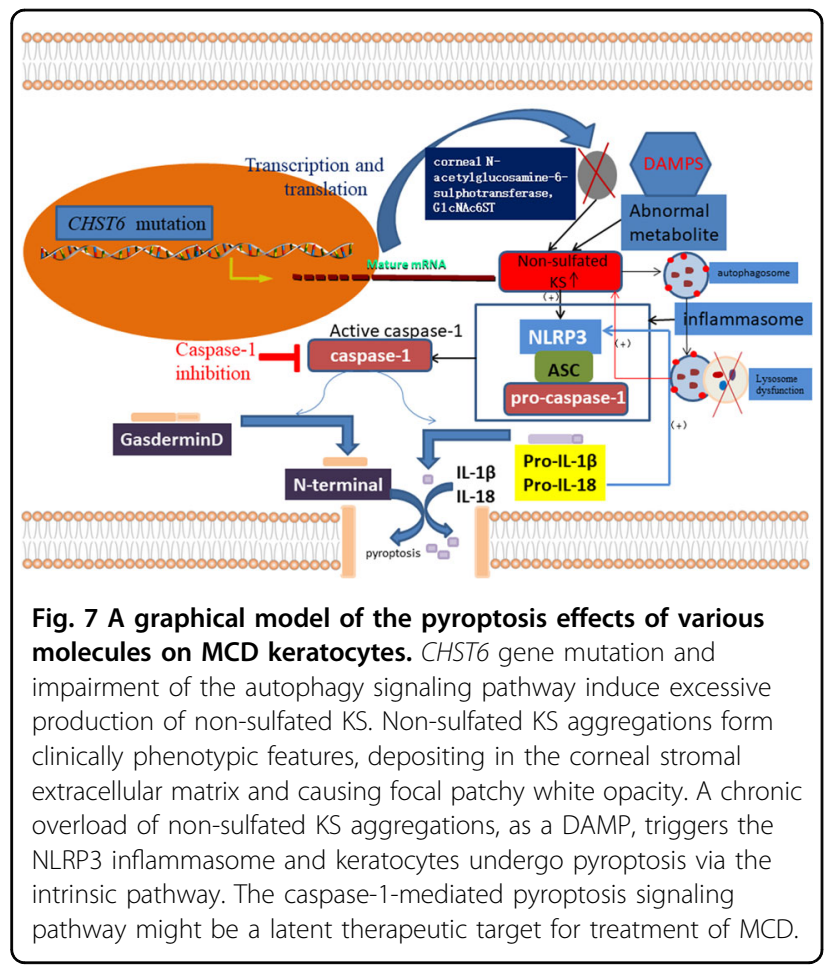

consideration. Notably, local application of Ac-YVADCMK in the form of eye drops might be proved effective in decreasing the corneal opacification associated with MCD.

In summary, a family with a homozygous CHST6 mutation was identified in Northeast China (Supplementary Fig. 2). We propose the possibility that impaired autophagy activates the NLRP3-caspase- 1 inflammasome pathway $^{53}$ and the subsequent activation of apoptosis triggers pyroptosis via a caspase-3-mediated pathway that results in cleavage of $\mathrm{GSDME}^{54,55}$. Multiple signaling pathways participate in MCD and determine cell fate. We postulate that pyroptosis is implicated in the pathogenic processes of MCD (Fig. 7). Taken together, our findings indicate that supplementation with the CTSD enzyme and administration of Ac-YVAD-CMK may represent a therapeutic strategy for the prevention of MCD.

\section{Materials and methods}

\section{Patients and control subjects}

Three patients from 3 unrelated families received clinical diagnoses of MCD by three doctors using slit-lamp biomicroscopy in the First Affiliated Hospital of Harbin Medical University; anterior segment optical coherence tomography was also analyzed in this study. Control subjects were selected from 50 individuals with no visual impairment. Informed consent was obtained from all patients and their family members in agreement with the Declaration of Helsinki for research involving human subjects. Approvals for genetic testing were obtained from the First Affiliated Hospital of Harbin Medical University.

\section{Materials}

The following Reagents and antibodies were used in this study: Dulbecco's Modified Eagle Media: Nutrient Mixture F-12 (Hyclone, UT, USA); $1 \times$ phosphate buffered saline $(1 \times$ PBS; Hyclone, UT, USA); Fetal bovine serum (ExCell Bio, Australian); Hydrogen peroxide $\left(\mathrm{H}_{2} \mathrm{O}_{2}\right)$ (Chemistry Industry Co, Shandong, China); Cell Counting Kit-8 (Beyotime, Shanghai, China); ECL developer (Beyotime, Shanghai, China); caspase-1 inhibitor AcTYR-VAL-ALA-ASP-CMK (Ac-YVAD-CMK) (Cayman Chemical, MI, USA); lysosomal inhibitor bafilomycin-A1 (Aladdin, Shanghai, China); Primary antibodies: antiNLRP3, anti-caspase-1, anti-IL-1 $\beta$, anti-CTSD, and antiGSDMD (Abcam, Cambridge, MA, USA); anti-keratan sulfate (5D4) (MD bioproducts, MN, USA); anti-GAPDH (Proteintect, IL, USA); anti-p62 and anti-LC3 (Cell Signaling Technology, MA, USA); TWEEN-20 (Solarbio, Beijing, China); HRP-conjugated secondary antibody (Zsbio, Beijing, China); LysoTracker Green DND-26 (Cell Signaling Technology, MA, USA).

\section{Methods}

\section{Limbus tissue primary culture and cell treatment}

Primary keratocytes were acquired from normal donors from the Heilongjiang Province Eye Bank and from mutation-type MCD patients who underwent penetrating or lamellar keratoplasty at the First Affiliated Hospital of Harbin Medical University. Cells were represented by 3 unrelated families and various MCD patients and 3 various normal donors. The limbus tissue of the MCD patients in this study and the limbus tissue of normal donors were taken for primary culture. The tissues were washed three times with $1 \times$ PBS containing $500 \mathrm{U} / \mathrm{ml}$ penicillin and $500 \mu \mathrm{g} / \mathrm{ml}$ streptomycin, and the corneal epithelium, endothelium, sclera, and conjunctiva were removed completely. The limbus tissue was then carefully separated and disintegrated into $1-2 \mathrm{~mm}^{3}$ pieces, and complete culture media was added after achieving full attachment of the tissues. The primary cell cultures were incubated at $37^{\circ} \mathrm{C}$ in $5 \% \mathrm{CO}_{2}$. The primary cell cultures were observed daily, and the medium was changed every 3 or 4 days. For subculturing, the cells were digested with 0.05\% trypsin and $5.0 \mathrm{mmol} / \mathrm{L}$ Ethylene Diamine Tetraacetie Acid (Gibco, NY, USA) when the density of the cells had reached $80-90 \%$ and the cells were transferred to culture flasks containing complete culture media.

\section{DNA extraction and gene sequencing}

Genomic DNA was isolated from peripheral blood leukocytes of MCD patients using a DNA extraction kit (Tiangen, Guangzhou, China) according to the 
manufacturer's instructions. Three pairs of primers $(1,2$, and 3, designed by Akama et al.) were used to amplify the region of the open reading frame of CHST6 (ref. ${ }^{6}$ ). Each PCR reaction was performed in a $50 \mu \mathrm{L}$ reaction mixture consisting of genomic DNA (100 ng) and $25 \mu \mathrm{L}$ of PrimeSTAR HS Premix DNA polymerase (Takara, Kusatsu, Japan) containing PrimeSTAR HS DNA Polymerase, dNTP Mixture and PrimeSTAR HS Buffer. Amplification reactions were performed under the following conditions: 5 min of denaturation at $98^{\circ} \mathrm{C}$, followed by 35 cycles of denaturation at $98{ }^{\circ} \mathrm{C}$ for $10 \mathrm{~s}$, annealing for $15 \mathrm{~s}$ at $55^{\circ} \mathrm{C}$ (for the middle coding region) or at $57^{\circ} \mathrm{C}$ (for the $5^{\prime}$ and $3^{\prime}$ coding regions), extension at $72{ }^{\circ} \mathrm{C}$ for $45 \mathrm{~s}$, and a further extension step at $72{ }^{\circ} \mathrm{C}$ for $7 \mathrm{~min}$. The PCR products were separated by agarose gel electrophoresis. Bidirectional sequencing was performed with a DNA sequencer (model 3730; Applied Biosystems, CA, USA).

\section{Treatment of keratocytes}

Cells in the logarithmic growth phase were collected and co-cultured with various concentrations of $\mathrm{H}_{2} \mathrm{O}_{2}$ and Ac-YVAD-CMK for the required time periods. $\mathrm{H}_{2} \mathrm{O}_{2}$ was diluted in Dulbecco's Modified Eagle Media: Nutrient Mixture F-12 and used at a $10 \mathrm{mM}$ concentration. AcYVAD-CMK and bafilomycin-A1 were dissolved in dimethyl sulfoxide, and used at $20 \mathrm{mg} / \mathrm{mL}$ and $1 \mathrm{mg} / \mathrm{mL}$, respectively, and then diluted in Dulbecco's Modified Eagle Media: Nutrient Mixture F-12.

\section{Inverted phase-contrast microscopy}

Cell morphology was observed by inverted phasecontrast microscopy when cells had entered the logarithmic growth phase. After treatment, the cell morphology was observed with an inverted phase-contrast microscope, and digital images were captured.

\section{Histological and transmission electron microscopy (TEM) observation of corneal tissue and Keratocytes}

Histological and TEM studies were performed on corneal flaps obtained from patients with MCD who had undergone corneal transplantation. Histological analysis of $4 \mu \mathrm{m}$ thick sections of paraffin-embedded corneal flap was performed in a patient with MCD after keratoplasty. The corneal tissues were stained with periodic acid Schiff stain and Alcian blue for light microscopy. Keratocytes and corneal tissues were also prepared for thin sections by fixing specimens with $2.5 \%(\mathrm{v} / \mathrm{v})$ glutaraldehyde in $0.1 \mathrm{M}$ for $2 \mathrm{~h}$, rinsing with 3 changes of $1 \times \mathrm{PBS}$; and post-fixing with $1 \%(\mathrm{v} / \mathrm{v}) \mathrm{OsO}_{4}$ in $1 \times \mathrm{PBS}$ for $2 \mathrm{~h}$. The specimens were washed, dehydrated in a graded ethanol series, and embedded in epoxy (low-viscosity agar) resin following standard protocols. Ultrathin sections were collected on carbon-coated 100 mesh copper grids and stained with $1 \%$ uranyl acetate and $1 \%$ lead citrate. The sections were viewed at $80 \mathrm{kV}$ in a Hitach-H7650 TEM.

\section{Western blotting}

Cells were collected and lysed in RIPA buffer (Beyotime, Shanghai, China) containing 1\% phenyl methyl sulfonyl fluoride (Beyotime, Shanghai, China). The protein concentration was calculated with a bicinchoninic acid protein assay kit (Beyotime, Shanghai, China). The protein was separated on a $12.5 \%$ sodium dodecyl sulfatepolyacrylamide gel electrophoresis (SDS-PAGE) gel and then transferred to a polyvinylidene difluoride $(0.22 \mu \mathrm{m})$ membrane (Millipore Corp, Atlanta, GA, USA) by wet transfer. After blocking with $8 \%$ skimmed milk powder, the polyvinylidene difluoride membrane was incubated overnight with the following main antibodies at $4{ }^{\circ} \mathrm{C}$ : antiNLRP3, anti-caspase-1, anti-IL-1 $\beta$, anti-GSDMD, antip62, anti-LC3, and anti-CTSD were respectively at $1 / 1000$ dilution. Anti-keratan sulfate (5D4) was at 1/250 dilution and anti-GAPDH was at $1 / 2000$ dilution. After three washes in PBST $(1 \times$ PBS containing 0.05\% TWEEN-20), the membrane was incubated with the appropriate HRPconjugated secondary antibody (1:5000) for $1 \mathrm{~h}$ at room temperature using ECL developer. An imaging system (Tanon 4600, Shanghai, China) was used to detect and analyze the signals.

\section{Real-time quantitative reverse transcription $P C R$}

Total RNA was extracted from cells using Trizol reagent (Invitrogen, CA, USA) according to the manufacturer's instructions, the concentration of RNA was detected by a NanoDrop Spectrophotometer (NanoDrop Technologies, Wilmington, DE, USA), and $1 \mu \mathrm{g}$ of total RNA was reverse transcribed into cDNA using a Reverse Transcription Kit (Takara, Kusatsu, Japan). The Reverse Transcription reaction consisted of $1 \mu \mathrm{g}$ RNA, $2 \mu \mathrm{L} 5 \times \mathrm{RT}$ Buffer, $0.5 \mu \mathrm{L}$ primer Mix, $0.5 \mu \mathrm{L}$ RT Enzyme Mix, and $6 \mu \mathrm{L}$ nuclease-free water in a total volume of $10 \mu \mathrm{L}$. Reactions were performed in an Eppendorf PCR System (Eppendorf, Hamburg, Germany) for $15 \mathrm{~min}$ at $37^{\circ} \mathrm{C}$, followed by heat inactivation for $5 \mathrm{~min}$ at $95^{\circ} \mathrm{C}$. The $10 \mu \mathrm{L}$ RT reaction mix was then held at $-20^{\circ} \mathrm{C}$. Primers for NLRP3, caspase-1, IL-1 $\beta$, and GAPDH were designed and synthesized by Corporation (Sangon, Shanghai, China). A 480 II Real-time PCR Instrument (Roche, Basel, Switzerland) was used with a $20 \mu \mathrm{L}$ PCR reaction mixture that included $2 \mu \mathrm{L}$ cDNA, $10 \mu \mathrm{L} 2 \times$ LightCycler ${ }^{\circledR} 480$ SYBR Green Realtime PCR Master Mix (TOYOBO, Osaka, Japan), $0.8 \mu \mathrm{L}$ forward primer, $0.8 \mu \mathrm{L}$ reverse primer, and $6.4 \mu \mathrm{L}$ nuclease-free water. Reactions were incubated in a 96-well optical plate at $95^{\circ} \mathrm{C}$ for $30 \mathrm{~s}$; followed by 40 cycles of $95^{\circ} \mathrm{C}$ for $5 \mathrm{~s}, 55^{\circ} \mathrm{C}$ for $10 \mathrm{~s}$, and $72{ }^{\circ} \mathrm{C}$ for $15 \mathrm{~s}$. Each sample was run in triplicate for analysis. At the end of the PCR cycles, melting curve analysis was performed 
to validate the specific generation of the expected PCR product. All experiments were done in triplicate. The expression levels of RNAs were normalized to glyceraldehyde-3-phosphate dehydrogenase and were calculated using the $2^{-\Delta \Delta \mathrm{Ct}}$ method.

\section{Cell proliferation assay}

A cell proliferation test kit was used following the manufacturer's instructions. Keratocytes from patients with MCD and a healthy control group were inoculated into 96-well plates, and a Cell Counting Kit-8 solution was added after appropriate time ( $24 \mathrm{~h}, 48 \mathrm{~h}$, and $72 \mathrm{~h}$ ). Before detection, $10 \mu \mathrm{L}$ of CCK- 8 reagent was added to the culture medium in each well and the plate was incubated in $37^{\circ} \mathrm{C}$ in $5 \% \mathrm{CO}_{2}$ incubator for $2 \mathrm{~h}$. The absorbance at $450 \mathrm{~nm}$ was read with a microplate reader (Bio-Rad, CA, USA) and all experiments were performed in triplicate.

\section{LysoTracker Green DND-26 labeling and FACS analysis}

LysoTracker Green dye stains cellular acidic compartments and visualizes enlarged lysosomes. Keratocytes were stained with LysoTracker Green according to the manufacturer's instructions by incubating them with the dye for $30 \mathrm{~min}$ at $37^{\circ} \mathrm{C}$. The proportion of LysoTrackerpositive cells was measured by flow cytometry.

\section{Statistical methods}

The measurements were expressed as means \pm standard deviation. One-way ANOVA was used to compare the data of multiple groups, and a Student's $t$-test was used to compare the data of two groups. All statistical analyses were performed using GraphPad software (GraphPad Prism 8, GraphPad Software, La Jolla, CA, USA). A value of $p<0.05$ was considered significant (" $p<0.05,{ }^{* *} p<0.01$, ${ }^{* * * *} p<0.001, \mathrm{~ns}=$ no significance). The individual experiments were repeated at least three times and representative data are displayed.

\section{Acknowledgements}

The authors thank the lab staff for their providing technical and writing assistance. This work was supported by the Heilongjiang Postdoctoral fund (Grant No. LBH-Z18185), the Heilongjiang Doctor Fund (Grant No. 2020B03), and the Heilongjiang provincial colleges and universities basic scientific research fund (Grant No. 2018-KYYWF-0484).

\section{Conflict of interest}

The authors declare that they have no conflict of interest.

\section{Publisher's note}

Springer Nature remains neutral with regard to jurisdictional claims in published maps and institutional affiliations.

The online version of this article (https://doi.org/10.1038/s41420-020-00320-z) contains supplementary material, which is available to authorized users.
Received: 11 July 2020 Revised: 18 August 2020 Accepted: 27 August 2020 Published online: 12 September 2020

References

1. Sultana, A. et al. Novel mutations of the carbohydrate sulfotransferase- 6 (CHST6) gene causing macular corneal dystrophy in India. Mol. Vis. 9, 730-734 (2003).

2. Aggarwal, S., Peck, T., Golen, J. \& Karcioglu, Z. A. Macular corneal dystrophy: a review. Sur. Ophthalmol. 63, 609-617 (2018).

3. Sogutlu Sari, E. et al. Deep anterior lamellar keratoplasty versus penetrating keratoplasty for macular corneal dystrophy: a randomized trial. Am. J. Ophthalmol. 156, 267-274 (2013).

4. Marcon et al. Recurrence of corneal stromal dystrophies after penetrating keratoplasty. Cornea 22, 19-21 (2003).

5. Weiss, J. S. et al. IC3D classification of corneal dystrophies- edition 2. Cornea 34, 117-159 (2015).

6. Akama, T. O. et al. Macular corneal dystrophy type I and type II are caused by distinct mutations in a new sulphotransferase gene. Nat. Genet. 26, 237-241 (2000).

7. Akama T. O. \& Fukuda M. N. Carbohydrate (N-Acetylglucosamine 6-O) sulfotransferase 5 and 6 (CHST5, 6). (eds Taniguchi N., Honke K., Fukuda M., Narimatsu H., Yamaguchi Y. \& Angata T). Handbook of Glycosyltransferases and Related Genes, 1005-1014 (Springer Japan, Tokyo, 2014).

8. Lewis, D. et al. Ultrastructural localization of sulfated and unsulfated keratan sulfate in normal and macular corneal dystrophy type I. Glycobiology 10, 305-312 (2000)

9. Hayashida, Y. et al. Matrix morphogenesis in cornea is mediated by the modification of keratan sulfate by GlcNAc 6-O-sulfotransferase. Proc. Natl Acad. Sci. USA 103, 13333-13338 (2006).

10. Davis, B. K., Wen, H. \& Ting, J. P. The Inflammasome NLRs in immunity, inflammation, and associated diseases. Annu. Rev. Immunol. 29, 707-735 (2011).

11. Fann, D. Y. et al. Intravenous immunoglobulin suppresses NLRP1 and NLRP3 inflammasome-mediated neuronal death in ischemic stroke. Cell Death Dis. 4, e790 (2013)

12. Liu, D., Zeng, X., Li, X., Mehta, J. L. \& Wang, X. Role of NLRP3 inflammasome in the pathogenesis of cardiovascular diseases. Basic Res. Cardiol. 113, 5 (2017).

13. Mortezaee, K., Khanlarkhani, N., Beyer, C. \& Zendedel, A. Inflammasome: its role in traumatic brain and spinal cord injury. J. Cell. Physiol. 233, 5160-5169 (2018).

14. $\mathrm{Hu}, \mathrm{B}$. et al. Inflammation-induced tumorigenesis in the colon is regulated by caspase-1 and NLRC4. Proc. Natl Acad. Sci. USA 107, 21635-21640 (2010).

15. Bauernfeind, F. G. et al. Cutting edge: NF-kappaB activating pattern recognition and cytokine receptors license NLRP3 inflammasome activation by regulating NLRP3 expression. J. Immunol. 183, 787-791 (2009).

16. Franchi, L., Munoz-Planillo, R. \& Nunez, G. Sensing and reacting to microbes through the inflammasomes. Nat. Immunol. 13, 325-332 (2012).

17. Franchi, L. et al. Cytosolic Double-Stranded RNA Activates the NLRP3 Inflammasome via MAVS-Induced Membrane Permeabilization and K+ Efflux. J. Immunol. 193, 4214-4222 (2014).

18. Park, J. H., Jeong, S. Y., Choi, A. J. \& Kim, S. J. Lipopolysaccharide directly stimulates Th17 differentiation in vitro modulating phosphorylation of RelB and NF-kappa B1. Immunol. Lett. 165, 10-19 (2015).

19. Zhao, Y., Shi, J. \& Shao, F. Inflammatory caspases: activation and cleavage of gasdermin-D in vitro and during pyroptosis. Methods mol. boil 1714, 131-148 (2018).

20. Mathiassen, S. G., De Zio, D. \& Francesco, C. Autophagy and the cell cycle: a complex landscape. Front. Oncol. 7, 51 (2017).

21. Marques, A. R. A. et al. Enzyme replacement therapy with recombinant proCTSD (cathepsin D) corrects defective proteolysis and autophagy in neuronal ceroid lipofuscinosis. Autophagy 16, 811-825 (2020).

22. Wang, L. et al. CHST6 mutation screening and endoplasmatic reticulum stress in macular corneal dystrophy. Oncotarget 8, 96301-96312 (2017).

23. Yang, C. J., SunderRaj, N., Thonar, E. J. \& Klintworth, G. K. Immunohistochemical evidence of heterogeneity in macular corneal dystrophy. Am. J. Ophthalmol. 106, 65-71 (1988)

24. Klintworth, G. K. \& Smith, C. F. Abnormalities of proteoglycans synthesised by corneal organ cultures derived from patients with macular corneal dystrophy. Lab. Invest. 48, 603-612 (1983). 
25. Midura, R. J. et al. Proteoglycan biosynthesis by human corneas from patients with types 1 and 2 macular corneal dystrophy. J. Biol. Chem. 265, 15947-15955 (1990).

26. Hassell, J. R., Newsome, D. A., Krachmer, J. H. \& Rodrigues, M. M. Macular corneal dystrophy: failure to synthesize a mature keratan sulfate preteoglycan. Proc. Natl Acad. Sci. USA 77, 3705-3709 (1980).

27. Kabeya, Y. et al. LC3, a mammalian homologue of yeast Apg8p, is localized in autophagosome membranes after processing. EMBO J. 19, 5720-5728 (2000)

28. Chazotte, B. Labeling lysosomes in live cells with LysoTracker. Cold Spring Harb. Protoc. 2011, pdb.prot5571 (2011).

29. Cermak, S. et al. Loss of cathepsin B and L leads to lysosomal dysfunction, NPC-like cholesterol sequestration and accumulation of the key Alzheimer's proteins. PLOS ONE 11, e0167428 (2016).

30. Mizushima, N. \& Yoshimori, T. How to interpret LC3 immunoblotting. Autophagy 3, 542-545 (2007).

31. Rosenfeld, M. G., Kreibich, G., Popov, D., Kato, K. \& Sabatini, D. D. Biosynthesis of Iysosomal hydrolases: their synthesis in bound polysomes and the role of COand post-translational processing in determining their subcellular distribution. J. Cell Biol. 93, 135-143 (1982).

32. Yamamoto, A. et al. Bafilomycin A1 prevents maturation of autophagic vacuoles by inhibiting fusion between autophagosomes and lysosomes in rat hepatoma cell line, H-4-II-E cells. Cell Struct. Funct. 23, 33-42 (1998).

33. Kesavardhana, S., Malireddi, R. K. S. \& Kanneganti, T.-D. Caspases in cell death, inflammation, and gasdermin-induced pyroptosis. Annu. Rev. Immunol. 38 567-595 (2020).

34. Shi, J. et al. Inflammatory caspases are innate immune receptors for intracellular LPS. Nature 514, 187-192 (2014).

35. Silvia, A.-L. et al. Role of mitochondria ROS generation in ethanol-induced NLRP3 inflammasome activation and cell death in astroglial cells. Front. Cell. Neurosci. 8, 216 (2014).

36. Ray, A. M., Owen, D. E., Evans, M. L., Davis, J. B. \& Benham, C. D. Caspase inhibitors are functionally neuroprotective against oxygen glucose deprivation induced CA1 death in rat organotypic hippocampal slices. Brain Res. $\mathbf{8 6 7}$ 62-69 (2000)

37. Bridges, K. R. Ascorbic acid inhibits lysosomal autophagy of ferritin. J. Biol. Chem. 262, 14773-14778 (1987).

38. Kirkland, R. A., Adibhatla, R. M., Hatcher, J. F. \& Franklin, J. L. Loss of cardiolipin and mitochondria during programmed neuronal death: evidence of a role for lipid peroxidation and autophagy. Neuroscience 115, 587-602 (2002).

39. Djavaheri-Mergny, M. et al. NF-kB activation represses tumor necrosis factor-ainduced autophagy. J. Biol. Chem. 281, 30373-30382 (2006).

40. Byun, Y. J. et al. Protective effects of vacuolar $\mathrm{H}^{+}$-ATPase $\mathrm{C}$ on hydrogen peroxide-induced cell death in C6 glioma cells. Neurosci. Lett. 425, 183-187 (2007).
41. Scott, J. E. \& Haigh, M. Identification of specific binding sites for keratan sulfate proteoglycans and chondroitin-dermatan sulfate proteoglycans on collagen fibrils in cornea by the use of cupromeronic blue in 'criticalelectrolyte-concentration' techniques. Biochem. J. 253, 607-610 (1988).

42. Hassell, J. R., Newsome, D. A., Nakazawa, K., Rodrigues, M. M. \& Krachmer, J. H. Defective conversion of a glycoprotein precursor to keratan sulfate proteoglycan in macular corneal dystrophy. (eds Hacks, S. \& Wang, J). Extracellular Matrix. 397-406 (Academic Press, New York, 1982).

43. Ong, E. et al. Structure and function of HNK-1 sulfotransferase. Identification of donor and acceptor binding sites by site-directed mutagenesis. J. Biol. Chem. 274, 25608-25612 (1999).

44. Yaylacioglu, T. F. et al. Genetic analysis of CHST6 and TGFBI in Turkish patients with corneal dystrophies: Five novel variations in CHST6. Mol. Vis. 22, 1267-1279 (2016).

45. Emmanouilidou, E et al. Cell-produced alpha-synuclein is secreted in a calcium-dependent manner by exosomes and impacts neuronal survival. J. Neurosci. 30, 6838-6851 (2010).

46. Olzmann, J. A., Kopito, R. R. \& Christianson, J. C. The mammalian endoplasmic reticulum-associated degradation system. Cold Spring Harb. Perspect. Biol. 5 a013185 (2013).

47. Mathivanan, S., Ji, H. \& Simpson, R. J. Exosomes: extracellular organelles important in intercellular communication. J. Proteom. 73, 1907-1920 (2010).

48. Shetty, R. et al. Distinct ocular surface soluble factor profile in human corneal dystrophies. Ocul. Surf. 18, 237-248 (2020).

49. Aachoui, Y., Sagulenko, V., Miao, E. A. \& Stacey, K. J. Inflammasome-mediated pyroptotic and apoptotic cell death, and defense against infection. Curr. Opin. Microbiol. 16, 319-326 (2013).

50. Kayagaki, N. et al. Non-canonical inflammasome activation targets caspase-11. Nature 479, 117-121 (2011).

51. Scherz-Shouval, R. et al. Reactive oxygen species are essential for autophagy and specifically regulate the activity of Atg4. EMBO J. 26, 1749-1760 (2007).

52. Zhu, S., Zhou, J., Sun, X., Zhou, Z. \& Zhu, Q. ROS accumulation contributes to abamectin-induced apoptosis and autophagy via the inactivation of PI3K/AKT/ mTOR pathway in TM3 Leydig cells. J. Biochemical Mol. Toxicol. 34, e22505 (2020).

53. Su, S.-H., Wu, Y.-F., Lin, Q., Wang, D.-P. \& Hai, J. URB597 protects against NLRP3 inflammasome activation by inhibiting autophagy dysfunction in a rat model of chronic cerebral hypoperfusion. J. Neuroinflammation 16, 260 (2019).

54. Wang, Y. et al. Chemotherapy drugs induce pyroptosis through caspase-3 cleavage of a gasdermin. Nature 547, 99-103 (2017).

55. Yu, J. et al. Cleavage of GSDME by caspase-3 determines lobaplatin-induced pyroptosis in colon cancer cells. Cell Death Dis. 10, 193 (2019). 